\title{
Reimagining ocean governance using the keystone species concept
}

To the Editor - Scientists have an important role in communicating problems and providing policy advice. However, we can also play an instrumental role in reimagining how we interact with the planet and our fragile biosphere, including by practical facilitation of change processes. In their recent Comment, Golden et al. ${ }^{1}$ describe the limited capacity to sustainably manage ocean-based human activities and argue for a need to reimagine ocean governance. The question is, where to start if the ambition is to improve the global ocean?

In the 1960s, Robert T. Paine changed the field of ecology ${ }^{2}$. He experimentally removed starfish in study plots of 8 metres by 2 metres, observed the cascading ecological effects and then repeated the procedure. This work led to the keystone species concept ${ }^{3}$, suggesting that some species are more important than others in determining the structure and function of an ecosystem. Inspired by that concept, and when attempting to re-imagine ocean governance, my colleagues and I looked for actors at the global level that can influence the resilience of the ocean and connect humans with ecosystems across the planet. We identified thirteen transnational seafood corporations as 'keystone actors' and argued that they could have a disproportionate impact on the structure and function of the global seafood production system as a consequence of their size and global connectivity through networks of subsidiaries ${ }^{4}$. If they take on a leadership role for integrating ocean stewardship and sustainability into their operations, perhaps they could trigger global and cascading effects that would change business practices.

To test this hypothesis, we engaged in bilateral meetings with them to discuss the state of the ocean and the necessity for change in order to meet the Sustainable Development Goals. The eight largest seafood companies of the world agreed to participate in a global and informal dialogue between business and science about their responsibility for a sustainable ocean. The dialogue was a collaborative learning experience, where the scientific knowledge we provided - grounded in an understanding of the dynamics of marine ecosystems and their governance represented a starting point for novel thinking among the companies. It was also a unique opportunity for us to learn from them. The dialogue resulted in a signed commitment ${ }^{5}$ stating that signatories will take on a leadership role for ocean stewardship and lead a transformation towards more sustainable seafood production, in collaboration with science.
This initiative is intended to support the process of reimagining how to sustainably manage the ocean. Co-identifying and co-designing concrete solutions will take time and require substantial investment. However, the fact that this initiative now exists is sending a signal to the seafood industry - and beyond - that it is time to take sustainability seriously, and that corporations need to collaborate with the planet as a core business strategy. After all, these are actors with real ability to enable change and with incentives to do so. The planet needs novel approaches and interactions, and hopefully this initiative can stimulate a discussion about how scientists can use their skills and knowledge to support sustainability.

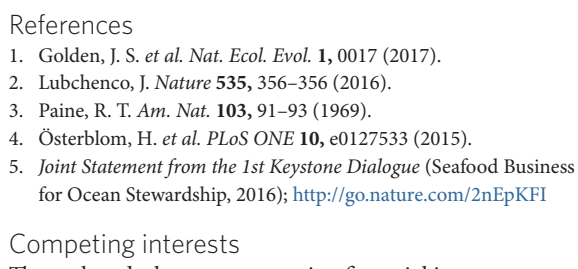

Competing interests

The author declares no competing financial interests.

Henrik Österblom

Stockholm Resilience Centre, Stockholm University, 10691 Stockholm, Sweden. e-mail: henrik.osterblom@su.se 